\title{
TaqIB polymorphism in cholesterol ester transfer protein (CETP) gene predicts future cardiovascular death in patients experiencing an acute coronary syndrome
}

\author{
Xavier Pillois ${ }^{1}$, Nahm Phuong Do Thi ${ }^{1}$, Annabel \\ Reynaud ${ }^{1}$, Daniel Benchimol ${ }^{1}$, Laurent Lagrost ${ }^{2}$ \\ and Jacques Bonnet ${ }^{1, *}$ \\ ${ }^{1}$ Institut Fédératif de Recherche $\mathrm{n}^{\circ} 4$ "Heart-Lung- \\ Vessel-Thrombosis" from the University Victor \\ Segalen of Bordeaux, France, and Inserm UMR828, \\ Pessac, France \\ ${ }^{2}$ Inserm, Research Center-UMR866, Dijon, France
}

\begin{abstract}
Background: Cholesterol ester transfer protein (CETP) plays a pivotal role in the remodelling of triglyceride (TG)-rich and high-density lipoprotein (HDL) particles. Sequence variations in the CETP gene may interfere with coronary atherosclerosis. However, clinical studies of various CETP polymorphisms have shown controversial data in coronary artery outcome. We aimed to investigate whether TaqIB CETP gene polymorphism could predict clinical outcome in a prospective cohort of patients hospitalized for an acute coronary syndrome (ACS).
\end{abstract}

Methods: Two hundred and seventy consecutive Caucasian patients hospitalized for an ACS, and having a significant coronary artery disease in at least one major vessel (stenosis $>50 \%$ ), were prospectively enrolled and followed for 57 months. The mean age was $65.1 \pm 12.5$ years, and $77 \%$ were males. One hundred and thirty-nine patients $(51.5 \%)$ suffered from unstable angina at inclusion and 131 patients (48.5\%) presented with an acute myocardial infarction (MI). The follow-up data were obtained from questionnaires. The major recurrent events recorded were 32 deaths comprising 28 cardiovascular deaths and 49 combined cardiovascular events (28 cardiovascular deaths, 19 non-fatal ACS and 2 non-fatal strokes). CETP genotyping was performed using a restriction fragment length polymorphism based method.

Results: A significant relation was found between B2B2 genotype and combined cardiovascular endpoint $(p<0.02)$, mainly driven by a link with cardiovascular death $(p<0.05)$. The hazard risk ratio for cardiovascular death associated with B2B2 genotype was 2.2 [95\% confidence interval $(\mathrm{Cl})$ : 1.01-4.94, $\mathrm{p}<0.05]$. In multivariate analyses, no modification

*Corresponding author: Jacques Bonnet, MD - Université 'Victor Segalen' de Bordeaux2 - Inserm unité 828, Avenue du Haut-Lévêque, 33600 Pessac, France

Phone: +33 (0)5 578919 70, Fax: +33 (0)5 563689 79,

E-mail: jacques.bonnet@inserm.fr

Received November 24, 2008; accepted June 5, 2009 except for a significant interaction with statin therapy was observed by inclusion of potential confounders for the association of B2B2 genotype with cardiovascular death.

Conclusions: These results suggest that patients homozygous for the $B 2$ allele and not taking statin had a strong increase of recurrent cardiovascular event after an initial acute coronary event. This cardiovascular risk seems to be corrected with statin therapy.

Clin Chem Lab Med 2009;47:1039-46.

Keywords: acute coronary syndrome; cardiovascular death; cholesterol ester transfer protein (CETP); gene polymorphism; prospective study.

\section{Introduction}

The inverse relationship between high-density lipoprotein cholesterol (HDL-C) and the incidence of cardiovascular disease $(1,2)$ has stimulated interest for pharmacological strategies for raising HDL-C levels. The finding that genetic deficiency of the cholesteryl ester transfer protein (CETP) in humans was associated with increased plasma HDL-C concentrations led to the concept that inhibition of CETP could be an interesting way for preventing coronary artery disease. CETP plays a central role in HDL metabolism, in particular by catalyzing the hetero-exchange of cholesteryl esters (CEs) from HDL particles to apolipoprotein $B(a p o B)$-containing particles, and triglycerides (TGs) from apoB lipoproteins to HDL particles (3). Numerous studies have shown that plasma concentrations of CETP are inversely related to HDL-C concentrations. Administration of the CETP inhibitor torcetrapib was shown to increase HDL-C concentrations by more than $50 \%$. However, the effectiveness of CETP inhibition as a strategy for anti-atherosclerotic therapy is controversial due to the recent unexpected association of torcetrapib with increased cardiovascular mortality (4-6). Today, the question is how to better identify patients who might derive some benefit from such a therapeutic approach. In this way, analysis of the relationship of genetic homozygous or heterozygous CETP deficiency to cardiovascular risk could be very interesting, but remains unclear (7-18). The risk of coronary heart disease might be lower in CETP-deficient heterozygotes, but CETP deficiency in Japanese-American men was associated with an increased prevalence of cardiovascular artery disease (CAD) despite modestly increased 
$\operatorname{HDL}-\mathrm{C}(9,18)$. A common polymorphism of the CETP gene located in intron 1 ( $T a q / B$ ) has consistently been shown to influence CETP activity and HDL-C concentrations. This polymorphism is non-functional by itself, but is in almost complete linkage disequilibrium with the $-629 C / A$ promoter polymorphism which directly modulates CETP gene transcriptional activity (19-22). After an acute coronary syndrome (ACS), patients with low plasma HDL-C receive clinical benefit from statin therapy. Since genetic variation of the CETP gene strongly affects HDL-C and possibly statin therapy, we conducted a prospective study to assess the potential effect of the TaqIB polymorphism on the rate of recurrent cardiovascular events in patients hospitalized for an acute coronary event.

\section{Materials and methods}

\section{Study design and patients}

Two hundred and eighty-four consecutive patients of Caucasian origin, hospitalized from October 1998 to January 2001 at the Cardiology Unit in Bordeaux University Hospital for an acute coronary event associated with a coronary artery disease confirmed by coronary angiography on the basis of a luminal diameter stenosis $\geq 50 \%$ in at least one coronary artery, were recruited for this study. Patients of any age and gender were recruited. Each gave written informed consent for blood collection for use in a confidential "deoxyribonucleic (DNA) bank", approved by the Local Research Ethics Committee. Key demographic characteristics at baseline were recorded using computerized angiographic data forms, including age, gender, risk factors, clinical presentation and biological data. Only patients presenting with an acute coronary event defined as unstable angina or acute myocardial infarction (MI) were recruited. The diagnosis of unstable angina included the presence of typical angina at rest associated with acute or transient ST segment or T wave changes without enzyme increases. Acute MI was diagnosed according to the occurrence of chest pain, increased myocardial enzymes (total and creatine kinase-MB and troponin $\mathrm{I} \geq$ twice the upper normal limit) and electrographic changes (ST elevation or depression). Hypercholesterolemia was defined as plasma low-density lipoprotein cholesterol (LDLC) concentrations $>2.58 \mathrm{mmol} / \mathrm{L}$; hypoalphalipoproteinemia was defined as plasma HDL-C concentrations $<1.032$ $\mathrm{mmol} / \mathrm{L}$ for men and $1.29 \mathrm{mmol} / \mathrm{L}$ for women; hypertriglyceridemia was defined as plasma TG concentrations $>1.7 \mathrm{mmol} / \mathrm{L}(23,24)$. Hypertension was defined 1) in nondiabetic patients as systolic pressure $>140 \mathrm{~mm} \mathrm{Hg}$ or diastolic pressure $>90 \mathrm{~mm} \mathrm{Hg} ; 2$ ) in diabetic patients as systolic pressure $>130 \mathrm{~mm} \mathrm{Hg}$ or diastolic pressure $>80 \mathrm{~mm} \mathrm{Hg}$; 3 ) as a history of hypertension requiring treatment (25). Body mass index was calculated as body weight in $\mathrm{kg}$ divided by the square of height in meters. Medications at discharge were noted. As indicated in Table 1, the mean age of the study population was $65.1 \pm 12.5$ years, with $77 \%$ male. At inclusion, 139 patients $(51.5 \%)$ suffered from unstable angina and 131 patients $(48.5 \%)$ presented with an acute MI. A previous $\mathrm{Ml}$ was found in 51 patients (18.9\%). Sixty-nine percent of the patients presented with multiple coronary stenosis, and $8 \%$ presented with a low ejection fraction (EF) of $<40 \%$.

\section{Follow-up}

Follow-up data were obtained from questionnaires sent to the patient or family, and the patient's general physician and
Table 1 Baseline characteristics of the study population $(n=270)$.

\begin{tabular}{ll}
\hline Age, years (mean \pm SD) & $65.1 \pm 12.5$ \\
Gender (male), n (\%) & $208(77)$ \\
Diabetes, n (\%) & $51(19)$ \\
BMI, kg/m² mean \pm SD & $25.8 \pm 3.9$ \\
Hypercholesterolemia, n (\%) & $207(77)$ \\
Hypertriglyceridemia, n (\%) & $93(34)$ \\
HypoHDLemia, n $(\%)$ & $115(43)$ \\
Hypertension, $\mathrm{n}(\%)$ & $187(69)$ \\
Current smoker, $\mathrm{n}(\%)$ & $82(30)$
\end{tabular}

Current smoker, n (\%)

$\mathrm{EF}<40 \%, \mathrm{n}(\%)$

MVD, n (\%)

186 (69)

$139(51)$

131 (49)

$\mathrm{MI}, \mathrm{n}(\%)$

Previous MI, n (\%)

51 (19)

Glycemia, mmol/L

$5.95+1.42$

Total cholesterol, $\mathrm{mmol} / \mathrm{L}$

$5.32 \pm 1.14$

$1.72 \pm 1.13$

$1.19 \pm 0.48$

$3.41 \pm 1.00$

$4.35 \pm 1.22$

$27.38 \pm 23.64$

ESR, $\mathrm{mm} / \mathrm{h}$

$260(96)$

Aspirin, n (\%)

$178(66)$

$\begin{array}{ll}\text { ACE inhibitor or ARAll, } \mathrm{n}(\%) & 140(52) \\ & 188(70)\end{array}$

mortality, n (\%)

$28(10)$

Cardiovascular death, n (\%)

$49(18)$

Medications are treatment during follow-up. BMI, body mass index; $E F$, ejection fraction; MVD, multiple vessels diseased; MI, myocardial infarction; TG, triglyceride; HDL-C, high-density lipoprotein cholesterol; LDL-C, low-density lipoprotein cholesterol; ESR, erythrocyte sedimentation rate; ACE, angiotensin converting enzyme; ARAll, angiotensin II receptor antagonists.

cardiologist. Questionnaires were sent 2 years following examination and then every other year. The following variables were recorded: death, cardiac death, stroke and ACS. Relevant clinical data were also analyzed for the patients who were readmitted or died in the hospital. Cardiac death was defined as that from any cardiac cause (sudden death, fatal $\mathrm{Ml}$, heart failure). Treatment during follow-up, although not standardized, was recorded. The mean followup period was 57 months. Among the 284 patients included in this study, 14 patients were lost to follow-up and excluded from the study. The final analysis was performed using the 270 patients with follow-up information. As indicated in Table 1, the major events recorded were 32 deaths, consisting of 28 deaths from cardiovascular causes, two from cancer, one from lymphoma and one from articular gangrene; and 49 combined cardiovascular events comprised of 28 deaths from cardiovascular causes, 19 non-fatal ACS and two non-fatal strokes. Median delay for combined end points was 12 months.

\section{Lipids and lipoproteins}

Total serum cholesterol (TC), TG, and HDL-C concentrations were determined using enzymatic assay kits (Roche modular, Roche Diagnostics SA, Meylan, France). LDL-C was calculated using the Friedewald equation (26). Lipid profiles 
Table 2 Distribution of follow-up events according to CETP TaqIB genotypes.

\begin{tabular}{lcccc}
\hline & $\begin{array}{l}\text { Number of } \\
\text { subjects }\end{array}$ & $\begin{array}{l}\text { Overall mortality } \\
(\mathrm{n}=32)\end{array}$ & $\begin{array}{l}\text { Cardiovascular death } \\
(\mathrm{n}=28)\end{array}$ & $\begin{array}{l}\text { Combined CV } \\
\text { event }(\mathrm{n}=49)\end{array}$ \\
\hline CETP TaqIB genotypes & & & & $6(7.2)$ \\
B1B1, $\mathrm{n}(\%)$ & 83 & $7(8.4)$ & $13(9.5)$ & $11(13.3)$ \\
B1B2, $\mathrm{n}(\%)$ & 137 & $16(11.7)$ & $9(17.6)$ & $23(16.8)$ \\
B2B2, $\mathrm{n}(\%)$ & 50 & $9(17.6)$ & 0.127 & $15(29.4)$ \\
Overall p-value & & 0.253 & $\mathbf{0 . 0 4 9}$ & $\mathbf{0 . 0 4 4}$ \\
p-Value for B2B2 & & 0.136 & $\mathbf{0 . 0 1 7}$ \\
\hline
\end{tabular}

Differences in genotypes frequencies were evaluated by the $\chi^{2}$-test. CV, cardiovascular. Bold: $p<0.05$.

obtained the day of ACS diagnosis were the only ones considered for analysis.

\section{Blood sampling for DNA analysis}

All blood samples for DNA analysis were collected at discharge. DNA was extracted from $200 \mu \mathrm{L}$ of the buffy coat of a centrifuged EDTA anticoagulated blood sample, with a QiaAmp ${ }^{\circledR}$ DNA minikit (QIAGEN S.A., Courtaboeuf, France) according to the manufacturer's protocol.

\section{CETP genotyping}

CETP genotyping was performed using a restriction fragment length polymorphism based method. Briefly, polymerase chain reaction (PCR) amplification was performed using primers surrounding the TaqIB polymorphism in intron 1 of the CETP gene: 5'-CAC ACC ACT GCC TGA TAA CC-3' (forward) and 5'-GTG ACC CCC AAC ACC AAA TA-3' (reverse). The amplification mixture included 25 pmol of each primer, $100 \mathrm{ng}$ genomic DNA, 1x GoTaq ${ }^{\circledR}$ reaction buffer, $1.5 \mathrm{mmol} / \mathrm{L}$ $\mathrm{MgCl}_{2}, 0.2 \mathrm{mmol} / \mathrm{L}$ of each dNTP, and $0.5 \mathrm{U}$ of GoTaq ${ }^{\circledR}$ DNA polymerase in a total volume of $25 \mu \mathrm{L}$ (Promega Corporation, Madison, WI, USA). Amplification was performed for 35 cycles of $30 \mathrm{~s}$ at $95^{\circ} \mathrm{C}, 15 \mathrm{~s}$ at $60^{\circ} \mathrm{C}$, and $15 \mathrm{~s}$ at $72^{\circ} \mathrm{C}$ with an initial denaturation period of $5 \mathrm{~min}$ at $95^{\circ} \mathrm{C}$. Approximately $20 \mu \mathrm{L}$ of PCR products were digested with the restriction enzyme Taql according to the recommendations of the supplier (Fermentas, Life Sciences, St. Rémy les chevreuse, France). Fragments were separated using $2 \%$ MP agarose gel (Boehringer Mannheim, Mannheim, Germany) and stained with ethidium bromide. One fragment of $505 \mathrm{bp}$ indicated the absence of the $T a q /$ restriction site (B2B2 genotype), two fragments of 415 and $90 \mathrm{bp}$ indicated the presence of the restriction site (B1B1), and three fragments of 505,415 , and $90 \mathrm{bp}$ indicated heterozygosity for the restriction site (B1B2).

\section{Statistical analysis}

Hardy-Weinberg equilibrium was tested using the $\chi^{2}$-test with two degrees of freedom. Differences between the groups of patients were evaluated with the unpaired t-test for continuous variables, and with the $\chi^{2}$-test for categorical variables. The cumulative survival plot in relation to CETP genotypes was estimated by the Kaplan-Meier method with use of the log-rank test. Hazard risk ratios according to CETP genotypes were estimated using Cox regression analysis. The interaction between the CETP TaqIB B2B2 genotype and statin treatment was tested by introducing a corresponding interaction term into the Cox model. In survival analyses, the p-value associated with the genotype was obtained by assuming a co-dominant allele effect (genotype entered as an ordinal variable 0,1 , or 2 ). A $p<0.05$ was considered statistically significant. All computations were carried out with NCSS 2000 (NCSS Inc, Kaysville, UT, USA).

\section{Results}

\section{CETP genotypes and clinical outcomes}

A significant association was found between the CETP TaqIB polymorphism and combined cardiovascular end point (Table 2). Homozygousity for the mutant

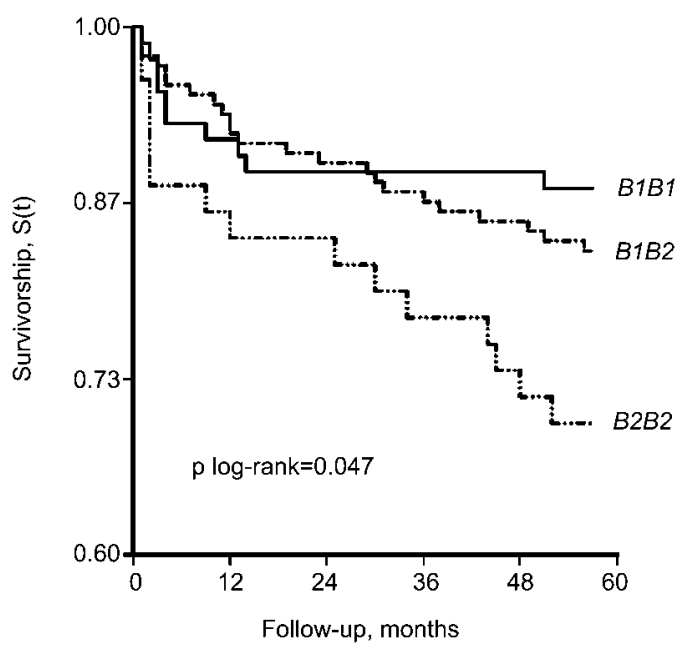

Figure 1 Combined cardiovascular event: survival analysis (Kaplan-Meier) for 270 coronary patients with ACS according to CETP TaqIB genotypes.

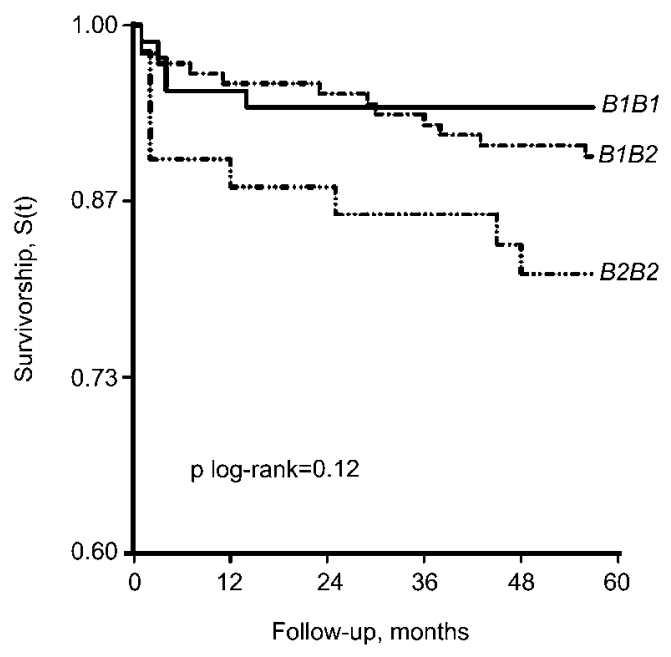

Figure 2 Death from a cardiovascular cause: survival analysis (Kaplan-Meier) for 270 coronary patients with ACS according to CETP TaqIB genotypes. 
Table 3 Baseline characteristics of patients according to cardiovascular death.

\begin{tabular}{|c|c|c|c|}
\hline & $\begin{array}{l}\text { With cardiovascular death } \\
(n=28)\end{array}$ & $\begin{array}{l}\text { Without cardiovascular death } \\
(\mathrm{n}=242)\end{array}$ & $\mathrm{p}$-Value \\
\hline Age, years (mean $\pm S D$ ) & $71.0 \pm 10.2$ & $64.5 \pm 12.6$ & 0.003 \\
\hline Gender (male), n (\%) & $19(68)$ & $189(78)$ & 0.22 \\
\hline Diabetes, n (\%) & $13(46)$ & $38(16)$ & $<0.001$ \\
\hline $\mathrm{BMI}, \mathrm{kg} / \mathrm{m}^{2}$ mean $\pm \mathrm{SD}$ & $27.2 \pm 4.9$ & $25.6 \pm 3.8$ & 0.12 \\
\hline Hypercholesterolemia, n (\%) & $18(64)$ & $189(78)$ & 0.10 \\
\hline Hypertriglyceridemia, n (\%) & $8(29)$ & $85(36)$ & 0.46 \\
\hline HypoHDLemia, n (\%) & $12(43)$ & $103(43)$ & ns \\
\hline Hypertension, n (\%) & $23(82)$ & $164(68)$ & 0.12 \\
\hline Current smoker, n (\%) & $7(25)$ & $75(31)$ & ns \\
\hline $\mathrm{EF}<40 \%, \mathrm{n}(\%)$ & $6(21)$ & $15(6)$ & 0.004 \\
\hline MVD, n (\%) & $23(82)$ & $163(69)$ & 0.15 \\
\hline Unstable angina, n (\%) & $18(64)$ & $121(50)$ & 0.15 \\
\hline MI, n (\%) & $10(36)$ & $121(50)$ & 0.15 \\
\hline Previous MI, n (\%) & $8(29)$ & $43(18)$ & 0.17 \\
\hline Glycemia, mmol/L & $6.83 \pm 1.83$ & $5.85 \pm 1.33$ & 0.01 \\
\hline Total cholesterol, $\mathrm{mmol} / \mathrm{L}$ & $5.54 \pm 1.67$ & $5.30 \pm 1.06$ & 0.48 \\
\hline TGs, mmol/L & $1.98 \pm 1.56$ & $1.70 \pm 1.08$ & 0.38 \\
\hline $\mathrm{HDL}-\mathrm{C}, \mathrm{mmol} / \mathrm{L}$ & $1.11 \pm 0.33$ & $1.20 \pm 0.49$ & 0.24 \\
\hline LDL-C, mmol/L & $3.74 \pm 1.63$ & $3.37 \pm 0.92$ & 0.29 \\
\hline Fibrinogen, g/L & $4.88 \pm 0.94$ & $4.29 \pm 1.23$ & 0.008 \\
\hline $\mathrm{ESR}, \mathrm{mm} / \mathrm{h}$ & $41.95 \pm 31.66$ & $26.00 \pm 22.35$ & 0.044 \\
\hline Aspirin, n (\%) & $26(93)$ & $234(97)$ & 0.31 \\
\hline$\beta$-Blocker, n (\%) & $11(39)$ & $167(69)$ & 0.001 \\
\hline ACE inhibitor or ARAll, $\mathrm{n}(\%)$ & $19(68)$ & $121(50)$ & 0.07 \\
\hline Statin, n (\%) & $18(64)$ & $170(70)$ & ns \\
\hline
\end{tabular}

Medications are those prescribed during follow-up. Continuous variables were analyzed with the unpaired t-test and categorical variables using the $\chi^{2}$-test. BMI, body mass index; EF, ejection fraction; MVD, multiple vessels diseased; MI, myocardial infarction; TG, triglyceride; HDL-C, high-density lipoprotein cholesterol; LDL-C, low-density lipoprotein cholesterol; ESR, erythrocyte sedimentation rate; $A C E$, angiotensin converting enzyme; ARA, angiotensin II receptor antagonists. Bold: $p<0.05$.

allele was more frequent in the patient group with a future combined cardiovascular event compared with non-carriers $(p<0.02)$. This association was primarily driven by cardiovascular mortality $(p<0.05)$, with no effect observed for non-fatal ACS or stroke. The relationship between genotypes and combined cardiovascular event or cardiovascular mortality are illustrated in the Cox survival plots (Figures 1 and 2).

\section{Characteristics of study population according to cardiovascular death}

Major traits significantly associated with cardiovascular death were age, diabetes mellitus, alteration of left ventricular function, and use of $\beta$-blockers (Table $3)$. It is also interesting to note a more severe inflammatory response to the initial coronary event.

Table 4 Hazard risk ratios of future cardiovascular death.

\begin{tabular}{|c|c|c|c|c|c|c|c|c|}
\hline \multirow{2}{*}{$\frac{\text { Categories }}{\text { Model } 1}$} & \multirow{2}{*}{$\begin{array}{l}\text { Variables } \\
B 2 B 2\end{array}$} & \multirow{2}{*}{$\frac{\beta}{0.803}$} & \multirow{2}{*}{$\frac{\text { SE }}{0.405}$} & \multirow{2}{*}{$\frac{\text { Z-Value }}{1.98}$} & \multirow{2}{*}{$\begin{array}{l}\mathrm{p} \text {-Value } \\
0.047\end{array}$} & \multirow{2}{*}{$\begin{array}{l}\mathrm{HR} \\
2.23\end{array}$} & \multicolumn{2}{|c|}{$\mathrm{Cl}(95 \%)$} \\
\hline & & & & & & & 1.01 & 4.93 \\
\hline \multirow[t]{3}{*}{ Model 2} & Age, years & 0.049 & 0.019 & 2.45 & 0.014 & 1.05 & 1.01 & 1.09 \\
\hline & Gender (male) & -0.161 & 0.425 & -0.38 & 0.706 & 0.85 & 0.37 & 1.96 \\
\hline & $B 2 B 2$ & 0.778 & 0.405 & 1.92 & 0.055 & 2.18 & 0.98 & 4.82 \\
\hline \multirow[t]{9}{*}{ Model 3} & Age, years & 0.042 & 0.021 & 1.95 & 0.051 & 1.04 & 1.00 & 1.09 \\
\hline & Gender (male) & -0.010 & 0.446 & -0.02 & 0.982 & 0.99 & 0.41 & 2.37 \\
\hline & Diabetes & 0.949 & 0.412 & 2.30 & 0.021 & 2.58 & 1.15 & 5.79 \\
\hline & $\mathrm{BMI}>25 \mathrm{~kg} / \mathrm{m}^{2}$ & 1.086 & 0.502 & 2.16 & 0.030 & 2.96 & 1.11 & 7.92 \\
\hline & Hypertension & 0.086 & 0.520 & 0.17 & 0.868 & 1.09 & 0.39 & 3.02 \\
\hline & $\beta$-Blocker & -0.720 & 0.424 & -1.70 & 0.090 & 0.49 & 0.21 & 1.12 \\
\hline & ACE inhibitor or ARAII & 0.190 & 0.447 & 0.43 & 0.671 & 1.21 & 0.50 & 2.91 \\
\hline & $\mathrm{EF}<40 \%$ & 1.348 & 0.547 & 2.46 & 0.014 & 3.85 & 1.32 & 11.24 \\
\hline & $B 2 B 2$ & 0.892 & 0.422 & 2.11 & 0.035 & 2.44 & 1.07 & 5.58 \\
\hline
\end{tabular}

Multiple variate Cox proportional hazards analyses were performed with cardiovascular death as the dependent variable and various independent variables as mentioned in the Table. HR, hazard risk ratio; B2B2, patients homozygous for B2 allele; BMI, body mass index; ACE, angiotensin converting enzyme; ARA, angiotensin II receptor antagonists; EF, ejection fraction. Bold: $\mathrm{p}<0.05$. 
Table 5 Hazard risk ratios of future cardiovascular death and interaction analyses with lipid profile parameters.

\begin{tabular}{|c|c|c|c|c|c|c|c|c|}
\hline \multirow{2}{*}{$\frac{\text { Categories }}{\text { Model } 1}$} & \multirow{2}{*}{$\begin{array}{l}\text { Variables } \\
B 2 B 2\end{array}$} & \multirow{2}{*}{$\frac{\beta}{0.803}$} & \multirow{2}{*}{$\frac{S E}{0.405}$} & \multirow{2}{*}{$\frac{\text { Z-Value }}{1.98}$} & \multirow{2}{*}{$\frac{p-\text { Value }}{0.047}$} & \multirow{2}{*}{$\frac{\mathrm{HR}}{2.23}$} & \multicolumn{2}{|c|}{$\mathrm{Cl}(95 \%)$} \\
\hline & & & & & & & 1.01 & 4.93 \\
\hline \multirow[t]{3}{*}{ Model 2} & Decreased HDL & 0.621 & 0.516 & 1.2 & 0.229 & 1.86 & 0.68 & 5.12 \\
\hline & $B 2 B 2$ & 1.13 & 0.605 & 1.87 & 0.062 & 3.10 & 0.95 & 10.16 \\
\hline & I & -0.923 & 0.983 & -0.94 & 0.348 & & & \\
\hline \multirow[t]{3}{*}{ Model 3} & Hypertriglyceridemia & -0.335 & 0.532 & -0.63 & 0.528 & 0.72 & 0.25 & 2.03 \\
\hline & $B 2 B 2$ & 0.809 & 0.500 & 1.62 & 0.105 & 2.25 & 0.84 & 5.98 \\
\hline & I & 0.222 & 0.885 & 0.25 & 0.801 & & & \\
\hline \multirow[t]{3}{*}{ Model 4} & Hypercholesterolemia & 0.511 & 0.756 & 0.68 & 0.499 & 1.67 & 0.38 & 7.34 \\
\hline & $B 2 B 2$ & 1.96 & 0.913 & 2.15 & 0.031 & 7.13 & 1.19 & 42.70 \\
\hline & I & -1.71 & 1.074 & -1.59 & 0.112 & & & \\
\hline \multirow[t]{3}{*}{ Model 5} & Statin therapy & 0.209 & 0.521 & 0.4 & 0.687 & 1.23 & 0.44 & 3.42 \\
\hline & $B 2 B 2$ & 1.82 & 0.633 & 2.87 & 0.004 & 6.15 & 1.78 & 21.31 \\
\hline & 1 & -1.624 & 0.820 & -1.99 & 0.047 & & & \\
\hline
\end{tabular}

Multiple variate Cox proportional hazards analyses were performed with cardiovascular death as dependent variable and various independent variables as mentioned in the Table. HR, hazard risk ratio; HDL, high-density lipoprotein; $B 2 B 2$, patients homozygous for $B 2$ allele; I, interaction term which correspond to the co-presence of the first two variables. Bold: $p<0.05$.

\section{Patient characteristics and genotype frequencies}

Overall allele frequencies in the study population were 0.56 for $B 1$ and 0.44 for $B 2$. The distribution of CETP TaqIB genotypes was B1B1 $30.74 \%$; B1B2 $50.74 \%$; and $B 2 B 218.52 \%$. These distributions conformed to the Hardy-Weinberg equilibrium. Overall, demographic and key clinical characteristics of patients were generally similar by genotype (data not shown). Importantly, distribution by genotype of clinical presentation at inclusion was similar (i.e., $44 \%$ of patients homozygous for B2 allele presented with an acute $\mathrm{Ml}$ vs. $50 \%$ in $B 1$ carriers, $\mathrm{n}=22$ and 111 , respectively, $\mathrm{p}=0.48$ ).

\section{Multivariate analyses}

On the basis of a recessive allele effect on risk for cardiovascular death, the hazard risk ratio associated with the TaqIB B2 allele was 2.23 [95\% confidence interval (Cl): 1.01-4.94; $\mathrm{p}=0.047$ ] (Table 4). To determine whether the CETP TaqIB B2B2 genotype predicted future fatal cardiovascular events independently of most significant clinical and therapeutic confounders, several models were fitted (Table 4). No modification was observed. Similarly, no modification of the association with B2B2 genotype was observed when hypoalphalipoproteinemia or hypertriglyceridemia status were included in the analysis. Hypercholesterolemia or statin therapy strongly modified this association (Table 5).

\section{Benefit of statin therapy according to CETP TaqIB B2B2 genotype}

A significant interaction between the CETP TaqIB $B 2 B 2$ genotype and statin therapy on cardiovascular mortality was observed (Table 5; $p$ for interaction $=0.047$ ). As indicated in Figure 3, patients homozygous for the CETP TaqIB B2 allele and not treated with statin had a higher prevalence of cardiovascular events during the follow-up period in comparison with patients carrying the $B 1$ allele. This apparent deleterious effect of the $B 2 B 2$ genotype disappears in patients treated with statins.

\section{Patient characteristics according to genotype and treatment status}

Patient characteristics differed somewhat by genotype and treatment (e.g., age, hyperlipidemia and concomitant therapy), but major baseline traits associated with the B2B2 genotype and absence of statin medication were hypercholesterolemia and hypertension (Table 6).

\section{Discussion}

The present prospective study reveals a significant higher frequency of $B 2$ homozygotes than carriers for the $B 1$ allele in patients experiencing a cardiovascular death or a combined cardiovascular event. On the basis of a recessive model, risk value (Hazard Ratio) for cardiovascular death in $B 2$ homozygous patients is estimated to be 2.23 with a $95 \% \mathrm{Cl}$ of $1.01-4.94$ $(p=0.047)$. This association remained significant even after the addition of potential confounding variables in the Cox regression. No modification can be seen when variables, such as age, gender, diabetes melli-

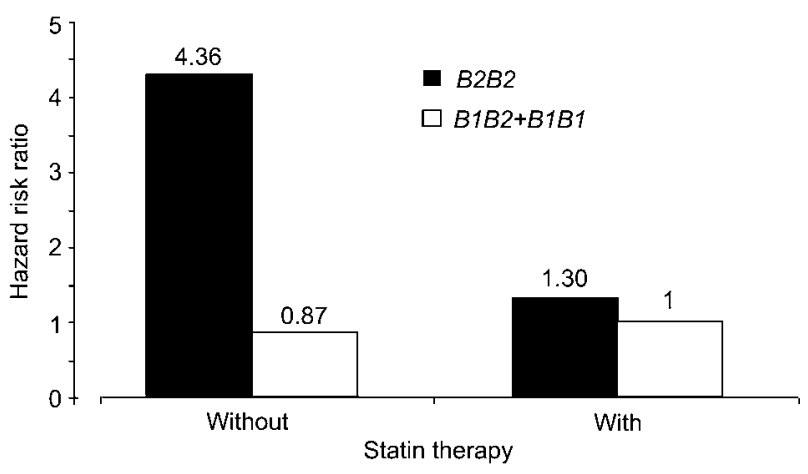

Figure 3 Hazard risk ratios of future cardiovascular death according to CETP TaqIB genotypes and statin therapy. 
Table 6 Baseline characteristics of patients according to statin treatment and CETP TaqIB genotypes.

\begin{tabular}{|c|c|c|c|c|}
\hline \multirow{2}{*}{$\frac{\text { Statin treatment }}{\text { CETP genotypes }}$} & \multirow{2}{*}{$\begin{array}{l}\text { Untreated } \\
B 2 B 2 \\
(n=14)\end{array}$} & \multicolumn{2}{|l|}{ Treated } & \multirow{2}{*}{$\begin{array}{l}\text { Untreated } \\
B 1^{\mathrm{a}} \\
(\mathrm{n}=68)\end{array}$} \\
\hline & & $\begin{array}{l}B 2 B 2 \\
(n=36)\end{array}$ & $\begin{array}{l}B 1^{a} \\
(n=152)\end{array}$ & \\
\hline Age, years (mean $\pm S D)$ & $72.9 \pm 10.1^{\mathrm{b}}$ & $63.9 \pm 13.4$ & $63.5 \pm 12.3$ & $68.0 \pm 12.0^{\mathrm{g}}$ \\
\hline Gender (male), n (\%) & $10(71)$ & $30(83)$ & $117(77)$ & $51(75)$ \\
\hline Diabetes n (\%) & $4(29)$ & $5(14)$ & $31(20)$ & $11(16)$ \\
\hline $\mathrm{BMI}, \mathrm{kg} / \mathrm{m}^{2}$ mean $\pm \mathrm{SD}$ & $25.2 \pm 3.9$ & $25.9 \pm 2.9$ & $26.1 \pm 4.3$ & $25.1 \pm 3.6$ \\
\hline Hypercholesterolemia, n (\%) & $7(50)^{c, d}$ & $31(86)$ & $115(76)$ & $54(79)$ \\
\hline Hypertriglyceridemia, n (\%) & $3(21)$ & $14(39)$ & 59 (39) & $17(25)^{\mathrm{g}}$ \\
\hline HypoHDLemia, n (\%) & $4(29)$ & $12(33)$ & $69(45)$ & $30(44)$ \\
\hline Hypertension, n (\%) & $13(93)^{d}$ & $27(75)$ & $104(68)$ & $43(63)$ \\
\hline Current smoker, n (\%) & $3(21)$ & $6(17)^{f}$ & $55(36)$ & $18(26)$ \\
\hline $\mathrm{EF}<40 \%, \mathrm{n}(\%)$ & $2(14)$ & $1(3)$ & $11(7)$ & $7(10)$ \\
\hline MVD, n (\%) & $11(78)$ & $21(58)$ & $106(71)$ & $48(73)$ \\
\hline Aspirin, n (\%) & $14(100)$ & $36(100)$ & $146(96)$ & $64(94)$ \\
\hline$\beta$-Blocker, n (\%) & $6(43)$ & $22(61)$ & $146(72)$ & $40(59)^{\mathrm{g}}$ \\
\hline ACE inhibitor, $\mathrm{n}(\%)$ & $9(64)$ & $16(44)$ & $75(49)$ & $40(59)$ \\
\hline Statin, n (\%) & $0(0)$ & $36(100)$ & $152(100)$ & $0(0)$ \\
\hline Overall mortality, n (\%) & $5(36)^{\mathrm{b}, \mathrm{e}}$ & $4(11)$ & $17(11)$ & $6(9)$ \\
\hline Cardiovascular death, n (\%) & $5(36)^{\mathrm{b}, \mathrm{e}}$ & $4(11)$ & $14(9)$ & $5(7)$ \\
\hline Combined cardiovascular event, $\mathrm{n}(\%)$ & $7(50)^{b, e}$ & $8(22)$ & $24(16)$ & $10(15)$ \\
\hline
\end{tabular}

${ }^{a} B 1$, carriers for $B 1$ allele; ${ }^{b} B 2 B 2$ homozygous patients without vs. with statin therapy, $p<0.05 ;{ }^{c} B 2 B 2$ homozygous patients without vs. with statin therapy, $\mathrm{p}<0.01 ;{ }^{\mathrm{d}} B 2 B 2$ homozygous vs. carriers for $B 1$ allele in patients without statin therapy, $\mathrm{p}<0.05$; ${ }^{\mathrm{e}} B 2 B 2$ homozygous vs. carriers for $B 1$ allele in patients without statin therapy, $\mathrm{p}<0.01 ;{ }^{\mathrm{f}} B 2 B 2$ homozygous vs. carriers for $B 1$ allele in patients with statin therapy, $p<0.05 ;{ }^{9} B 1$ carriers without vs. with statin therapy, $p<0.05$. Medications are treatment during follow-up. B2B2, patients homozygous for B2 allele; BMI, body mass index; EF, ejection fraction; MVD, multiple vessels diseased; $A C E$, angiotensin converting enzyme.

tus, arterial hypertension or heart failure (defined as an $\mathrm{EF}<40 \%$ ) were added in the model. Similarly, no modification was observed when variables, such as low concentrations of HDL-C or hypertriglyceridemia were added. One variable that significantly modified this association was the presence or absence of statin therapy. This suggests that patients homozygous for the $B 2$ allele and not taking statin had a strong likelihood of recurrent cardiovascular events after an initial acute coronary event, unstable angina or MI. This risk seems to be corrected with statin treatment.

Since its initial description, the relationship between the TaqIB genotype and the risk of CAD has been investigated in numerous population-based studies. Meta-analysis performed individual patient data from seven large, population-based studies and three randomized, placebo-controlled, pravastatin trials has shown that the Taql genotype was significantly associated with the risk of coronary artery disease, with a lower risk for B2 carriers. Usually the significant association between TaqIB genotype and CAD risk is largely mediated through HDL-C concentrations. Our results did not find a lower risk for $B 2 B 2$ individuals or mediation of the risk through HDL-C concentrations. These conflicting results could be due to the fact that our study analyzed recurrent cardiovascular events in patients initially recruited for an initial coronary event. The higher prevalence of cardiovascular events in $B 2 B 2$ could suggest a cardiovascular death risk independent of HDL-C concentrations. In our study, it did not appear to be dependant of potential interactions with TG concentrations, known to affect CETP activity and previously reported as potentially mediating the CAD risk of CETP (27). It is difficult to assume that the worst evolution of $B 2$ carriers could be due to more rapid progression of coronary atherosclerosis which is related to CETP mass and the $B 1$ allele (14). Moreover, in patients with coronary artery disease, a previous study demonstrated that the CETP/-629A allele, in nearly complete concordance with the $B 2$ allele, had a strong protective effect on future mortality from cardiovascular causes (7). All of these results suggest that $B 2$ carriers should be protective against future or recurrent coronary event.

In order to explain our results, we could not exclude a selection effect. B2B2 patients, theoretically protected against coronary artery disease and presenting with an acute coronary event, could be more sensitive to undetected or unknown risk factors leading to a more severe prognosis. In the same way, the apparent deleterious action of the $B 2$ allele could be linked to an associated genotype, such as hepatic lipase lowering gene variants that have been previously reported (27). The impact of the CETP genotype on risk mediated by a prothrombotic or proarrhythmic effects of CETP within the vessel wall or within ischemic myocardium is always possible. Nevertheless, our finding of a less favorable outcome in B2B2 subjects is in agreement with results reported by Mohrschladt et al. (16) in statin-treated patients with familial hypercholesterolemia.

Based on these results, we hypothesize that in patients with an ACS, a low CETP level and activity as 
observed in B2B2 subjects could be deleterious. This can lead to future fatal cardiovascular events by decreasing the reverse cholesterol transport from HDL and peripheral tissues to the liver under conditions of efficient hepatic apoB lipoprotein clearance. The strong amplification of this mechanism by statin therapy with the significant decrease in LDL-C concentrations could explain the disappearance of the deleterious action of CETP deficiency.

\section{Limitation}

The present study has limitations. First, the small population and small number of events preclude an exhaustive statistical analysis. Second, the sole inclusion of patients experiencing an ACS could result in selection bias. Moreover, we did not have the ability to evaluate lipid parameters before and after statin therapy. The results on the genotype-statin interaction should thus be considered as a hypothesis. Because we tested several primary and secondary hypotheses that were not independent, it was not possible to correct for multiple testing; hence, the p-values provided are nominal and require further confirmation. Finally, serum CETP concentrations and activity were not measured. Therefore, no association between them could be observed.

\section{Conclusions}

This study demonstrates an association between the B2B2 genotype in the CETP gene and risk of future cardiovascular death in patients experiencing an ACS. Specifically, patients at increased risk are those with an ACS who are not receiving statin medication and homozygous for the $B 2$ allele. We speculate that these patients express an increased sensitivity to less effective peripheral cholesterol removal. As the action of CETP may have different effects depending on the metabolic and/or clinical context, the question is whether CETP is a good marker and/or therapeutic target for patients at increased risk of coronary events.

\section{Acknowledgments}

We thank R. Cooke for revising the English version of this article. This work was supported by grants from the Conseil Regional d'Aquitaine, Federation Française de Cardiologie and the Medical Research Fund of the Groupe Hospitalier de Bordeaux and the Agence Nationale de la Recherche, ANR "Antherolip".

\section{References}

1. Gordon DJ, Probstfield JL, Garrison RJ, Neaton JD, Castelli WP, Knoke JD, et al. High-density lipoprotein cholesterol and cardiovascular disease. Four prospective American studies. Circulation 1989;79:8-15.
2. Gordon DJ, Rifkind BM. High-density lipoprotein - the clinical implications of recent studies. N Engl J Med 1989;321:1311-6.

3. Tall AR. Plasma cholesteryl ester transfer protein. J Lipid Res 1993;34:1255-74.

4. Bots ML, Visseren FL, Evans GW, Riley WA, Revkin JH, Tegeler $\mathrm{CH}$, et al. Torcetrapib and carotid intima-media thickness in mixed dyslipidaemia (RADIANCE 2 study): a randomised, double-blind trial. Lancet 2007;370:153-60.

5. Brousseau ME, Schaefer EJ, Wolfe ML, Bloedon LT, Digenio AG, Clark RW, et al. Effects of an inhibitor of cholesteryl ester transfer protein on $\mathrm{HDL}$ cholesterol. N Engl J Med 2004;350:1505-15.

6. Clark RW, Sutfin TA, Ruggeri RB, Willauer AT, Sugarman ED, Magnus-Aryitey G, et al. Raising high-density lipoprotein in humans through inhibition of cholesteryl ester transfer protein: an initial multidose study of torcetrapib. Arterioscler Thromb Vasc Biol 2004;24:490-7.

7. Blankenberg S, Rupprecht HJ, Bickel C, Jiang XC, Poirier $\mathrm{O}$, Lackner KJ, et al. Common genetic variation of the cholesteryl ester transfer protein gene strongly predicts future cardiovascular death in patients with coronary artery disease. J Am Coll Cardiol 2003;41:1983-9.

8. Boekholdt SM, Sacks FM, Jukema JW, Shepherd J, Freeman DJ, McMahon AD, et al. Cholesteryl ester transfer protein TaqIB variant, high-density lipoprotein cholesterol levels, cardiovascular risk, and efficacy of pravastatin treatment: individual patient meta-analysis of 13,677 subjects. Circulation 2005;111:278-87.

9. Borggreve $\mathrm{SE}$, Hillege HL, Wolffenbuttel $\mathrm{BH}$, de Jong PE, Zuurman MW, van der Steege G, et al. An increased coronary risk is paradoxically associated with common cholesteryl ester transfer protein gene variations that relate to higher high-density lipoprotein cholesterol: a population-based study. J Clin Endocrinol Metab 2006;91: 3382-8.

10. Carlquist JF, Muhlestein JB, Horne BD, Hart NI, Bair TL, Molhuizen HO, et al. The cholesteryl ester transfer protein Taq1B gene polymorphism predicts clinical benefit of statin therapy in patients with significant coronary artery disease. Am Heart J 2003;146:1007-14.

11. Carmena-Ramon R, Ascaso JF, Real JT, Najera G, Ordovas JM, Carmena R. Association between the TaqIB polymorphism in the cholesteryl ester transfer protein gene locus and plasma lipoprotein levels in familial hypercholesterolemia. Metabolism 2001;50:651-6.

12. de Grooth GJ, Zerba KE, Huang SP, Tsuchihashi Z, Kirchgessner $T$, Belder R, et al. The cholesteryl ester transfer protein (CETP) TaqIB polymorphism in the cholesterol and recurrent events study: no interaction with the response to pravastatin therapy and no effects on cardiovascular outcome: a prospective analysis of the CETP TaqIB polymorphism on cardiovascular outcome and interaction with cholesterol-lowering therapy. J Am Coll Cardiol 2004;43:854-7.

13. Freeman DJ, Samani NJ, Wilson V, McMahon AD, Braund PS, Cheng S, et al. A polymorphism of the cholesteryl ester transfer protein gene predicts cardiovascular events in non-smokers in the West of Scotland Coronary Prevention Study. Eur Heart J 2003;24:183342.

14. Kuivenhoven JA, Jukema JW, Zwinderman AH, de Knijff $\mathrm{P}$, McPherson R, Bruschke AV, et al. The role of a common variant of the cholesteryl ester transfer protein gene in the progression of coronary atherosclerosis. The Regression Growth Evaluation Statin Study Group. N Engl J Med 1998;338:86-93.

15. Liu S, Schmitz C, Stampfer MJ, Sacks F, Hennekens $\mathrm{CH}$, Lindpaintner $\mathrm{K}$, et al. A prospective study of TaqIB polymorphism in the gene coding for cholesteryl ester transfer protein and risk of myocardial infarction in middle-aged men. Atherosclerosis 2002;161:469-74. 
16. Mohrschladt MF, van der Sman-de Beer F, Hofman MK, van der Krabben M, Westendorp RG, Smelt AH. TaqlB polymorphism in CETP gene: the influence on incidence of cardiovascular disease in statin-treated patients with familial hypercholesterolemia. Eur J Hum Genet 2005;13: 877-82.

17. Takata M, Inazu A, Katsuda S, Miwa K, Kawashiri MA, Nohara A, et al. CETP (cholesteryl ester transfer protein) promoter $-1337 \mathrm{C}>\mathrm{T}$ polymorphism protects against coronary atherosclerosis in Japanese patients with heterozygous familial hypercholesterolaemia. Clin Sci (Lond) 2006;111:325-31.

18. Zhong S, Sharp DS, Grove JS, Bruce C, Yano K, Curb $\mathrm{JD}$, et al. Increased coronary heart disease in JapaneseAmerican men with mutation in the cholesteryl ester transfer protein gene despite increased HDL levels. J Clin Invest 1996;97:2917-23.

19. Corbex M, Poirier O, Fumeron F, Betoulle D, Evans A, Ruidavets JB, et al. Extensive association analysis between the CETP gene and coronary heart disease phenotypes reveals several putative functional polymorphisms and gene-environment interaction. Genet Epidemiol 2000;19:64-80.

20. Dachet C, Poirier O, Cambien F, Chapman J, Rouis M. New functional promoter polymorphism, CETP/-629, in cholesteryl ester transfer protein (CETP) gene related to CETP mass and high density lipoprotein cholesterol levels: role of $\mathrm{Sp} 1 / \mathrm{Sp} 3$ in transcriptional regulation. Arterioscler Thromb Vasc Biol 2000;20:507-15.

21. Drayna D, Lawn R. Multiple RFLPs at the human cholesteryl ester transfer protein (CETP) locus. Nucleic Acids Res 1987;15:4698.
22. Klerkx AH, Tanck MW, Kastelein JJ, Molhuizen HO, Jukema JW, Zwinderman $\mathrm{AH}$, et al. Haplotype analysis of the CETP gene: not TaqIB, but the closely linked $-629 \mathrm{C} \rightarrow \mathrm{A}$ polymorphism and a novel promoter variant are independently associated with CETP concentration. Hum Mol Genet 2003;12:111-23.

23. Third Report of the National Cholesterol Education Program (NCEP) Expert Panel on Detection, Evaluation, and Treatment of High Blood Cholesterol in Adults (Adult Treatment Panel III) final report. Circulation 2002;106: 3143-421.

24. Grundy SM, Brewer HB Jr, Cleeman JI, Smith SC Jr, Lenfant C. Definition of metabolic syndrome: report of the National Heart, Lung, and Blood Institute/American Heart Association conference on scientific issues related to definition. Circulation 2004;109:433-8.

25. Mancia G, De Backer G, Dominiczak A, Cifkova R, Fagard R, Germano G, et al. 2007 Guidelines for the management of arterial hypertension: The Task Force for the Management of Arterial Hypertension of the European Society of Hypertension (ESH) and of the European Society of Cardiology (ESC). Eur Heart J 2007;28:1462-536.

26. Friedewald WT, Levy RI, Fredrickson DS. Estimation of the concentration of low-density lipoprotein cholesterol in plasma, without use of the preparative ultracentrifuge. Clin Chem 1972;18:499-502.

27. van Acker BA, Botma GJ, Zwinderman AH, Kuivenhoven JA, Dallinga-Thie GM, Sijbrands EJ, et al. High HDL cholesterol does not protect against coronary artery disease when associated with combined cholesteryl ester transfer protein and hepatic lipase gene variants. Atherosclerosis 2007. 